\title{
An Assessment of Melatonin's Therapeutic Value in the Hypoxic-Ischemic Encephalopathy of the Newborn
}

\author{
Daniel P. Cardinali* \\ Faculty of Medical Sciences, Pontificia Universidad Católica Argentina, Buenos Aires, Argentina
}

Hypoxic-ischemic encephalopathy (HIE) is one of the most frequent causes of brain injury in the newborn. From a pathophysiological standpoint, a complex process takes place at the cellular and tissue level during the development of newborn brain damage in the absence of oxygen. Initially, the lesion is triggered by a deficit in the supply of oxygen to cells and tissues, causing a primary energy insufficiency. Subsequently, high energy phosphate levels recover transiently (the latent phase) that is followed by a secondary phase, in which many of the pathophysiological mechanisms involved in the development of neonatal brain damage ensue (i.e., excitotoxicity, massive influx of $\mathrm{Ca}^{2+}$, oxidative and nitrosative stress, inflammation). This leads to cell death by necrosis or apoptosis. Eventually, a tertiary phase occurs, characterized by the persistence of brain damage for months and even years after the HI insult. Hypothermia is the only

\section{OPEN ACCESS}

Edited by:

Francisco Capani,

University of Buenos Aires, Argentina

Reviewed by:

Dario Acuña-Castroviejo,

University of Granada, Spain

Emilio J. Sanchez-Barcelo, University of Cantabria, Spain

Germaine Escames,

University of Granada, Spain

*Correspondence:

Daniel P. Cardinal

daniel_cardinali@uca.edu.ar;

danielcardinali@fibertel.com.ar

Received: 01 September 2019 Accepted: 26 November 2019

Published: 10 December 2019

Citation:

Cardinali DP (2019) An Assessment of Melatonin's

Therapeutic Value

in the Hypoxic-Ischemic Encephalopathy of the Newborn. Front. Synaptic Neurosci. 11:34. doi: 10.3389/fnsyn.2019.00034 therapeutic strategy against HIE that has been incorporated into neonatal intensive care units with limited success. Thus, there is an urgent need for agents with the capacity to curtail acute and chronic damage in HIE. Melatonin, a molecule of unusual phylogenetic conservation present in all known aerobic organisms, has a potential role as a neuroprotective agent both acutely and chronically in HIE. Melatonin displays a remarkable antioxidant and anti-inflammatory activity and is capable to cross the bloodbrain barrier readily. Moreover, in many animal models of brain degeneration, melatonin was effective to impair chronic mechanisms of neuronal death. In animal models, and in a limited number of clinical studies, melatonin increased the level of protection developed by hypothermia in newborn asphyxia. This review article summarizes briefly the available therapeutic strategies in HIE and assesses the role of melatonin as a potentially relevant therapeutic tool to cover the hypoxia-ischemia phase and the secondary and tertiary phases following a hypoxic-ischemic insult.

Keywords: hypoxic-ischemic encephalopathy, hypothermia, melatonin, oxidative stress, inflammation, neurodegeneration

\section{INTRODUCTION}

According to the World Health Organization, for every day in 2015, 16,000 children aged under 5 died (World Health Organization [WHO], 2015). Forty-five per cent of those deaths were in newborns, mainly due to intrapartum-related complications and prematurity. In particular, hypoxic-ischemic encephalopathy (HIE) remains as a significant problem particularly in 
low-resource countries, where the rate of asphyxia is about 10-fold higher (10-20 per 1000 live births) than in developed countries (Lawn et al., 2005).

Intrapartum hypoxic-ischemic (HI) events including placental abruption, umbilical cord prolapse, obstructed labor, uterine rupture, and fetal infection result in impaired oxygenation and perfusion of vital organs in the fetus and newborn infant (Yildiz et al., 2017). HI injury to peripheral organs is often reversible (Yildiz et al., 2017). In contrast, HIE injury may lead to permanent neurological impairment. Survivors with long-term disability commonly have cerebral palsy including spastic quadriplegic and dyskinetic types (Schreglmann et al., 2019).

Knowledge of HIE pathophysiology derived in the description of potential therapeutic targets to reduce cerebral damage after asphyxia, with the consequent postulation of therapeutic strategies. This review article summarizes briefly the available therapeutic strategies in HIE and assesses the role of melatonin, a potentially relevant therapeutic tool to cover the hypoxiaischemia phase and the secondary and tertiary phases following a $\mathrm{HI}$ insult. Medical literature was identified by searching databases including (MEDLINE, EMBASE), bibliographies from published literature and clinical trial registries/databases. Searches were last updated on September 1, 2019.

\section{PATHOPHYSIOLOGY AND THERAPEUTIC STRATEGIES IN HIE}

A complex process takes place at the cellular and tissue level due to lack of oxygen (Yildiz et al., 2017).

The harmful mechanisms during the development of newborn brain damage by hypoxia can be grouped based on the time elapsed since their appearance (Yildiz et al., 2017). They comprise four phases (Figure 1): (a) hypoxia-ischemia phase; (b) latent phase; (c) secondary phase; (d) tertiary phase. At first, the injury is triggered by a deficit in the supply of oxygen to cells, causing a primary energy insufficiency. Subsequently, high energy phosphate levels may transiently recover (the latent phase), this phase elapsing for 3-15 h. In the secondary phase that followed, many of the pathophysiological mechanisms of neonatal brain damage are triggered. Excitotoxicity, massive influx of $\mathrm{Ca}^{2+}$, oxidative stress, inflammatory reaction and eventually cell death by apoptosis or necrosis are characteristics of the secondary phase that elapses from some hours to days. Finally, a tertiary phase ensues, characterized by persistent cerebral damage for months and years after the HI injury (Yildiz et al., 2017).

Insufficient oxygen delivery to the CNS is the initial event in HIE. It is produced either by hypoxia or by impaired cerebral blood flow due to hypovolemia or impaired circulation. Commonly, a combination of both events takes place (Yildiz et al., 2017). A decrease production of ATP and lactic acidosis occur in the primary energy failure after injury (Torres-Cuevas et al., 2019). Disruption of neuronal cell membrane leads to massive calcium entry to the cell, an event mediated by activation of $N$-methyl-D-aspartate (NMDA) receptor by excitotoxic neurotransmitters (glutamate, aspartate) (Pregnolato et al., 2019). Only very few therapeutic strategies have the capacity to control the primary energy failure. As discussed below, melatonin may be one of them.

A period of latency that lasts for some hours after primary energy failure gives the possibility for interventions to curtail prospective brain damage. If they are not provided, a secondary energy failure leads to HIE (Yildiz et al., 2017). Excitotoxicity, oxidative stress, inflammation and cell death characterize the secondary energy failure that ensues 6-48 h after hypoxic/ischemia (HI). In some infants, a tertiary phase of brain damage arises due to the presence of active mechanisms preventing regeneration of neurons. These mechanisms include a low-degree inflammation, impairment of oligodendrocyte maturation, impaired neurogenesis and axonal growth, and disrupted synaptogenesis. Myelin deficits and reduced plasticity can persist for months to years after the initial injury (Fleiss and Gressens, 2012).

The ischemia-reperfusion phenomenon that occurs after perinatal asphyxia triggers the increase in reactive oxygen species (ROS), a subsequent lipid and protein peroxidation and the stimulation of apoptotic or necrotic pathways in brain cells (Castillo-Melendez et al., 2004; Miller et al., 2012; Aridas et al., 2016; Martinez-Biarge et al., 2019). The increase in ROS is detectable very early after asphyxia (i.e., up to $30 \mathrm{~min}$ ) and may elapse for several days (Yan et al., 2005). Poorly developed innate antioxidative defense systems turn the newborn CNS very prone to oxidative stress (du Plessis and Volpe, 2002; Castillo-Melendez et al., 2013).

Neuroinflammation and oxidative damage interact each other. ROS trigger pro-inflammatory cytokine release and microglial activation, and conversely, microglia release free radicals and pro-inflammatory cytokines (Miller et al., 2012). The control of these early mechanisms of brain injury is generally considered an avenue for any promising neuroprotective strategy (Hassell et al., 2015).

The use of hypothermia as a neuroprotective therapy in neonatal HIE derives from the discovery of endogenous cooling mechanisms that are triggered by brain damage at birth (Burnard and Cross, 1958). The neuroprotective effect of hypothermia is related mainly to the reduction of brain metabolism (a 5\% decrease for each degree of temperature), a situation the moderates several metabolic routes triggered after suffocation (Laptook et al., 1995).

Only a modest improvement in mortality and long-term neurological morbidity is provided by hypothermia therapy in HIE (Roka and Azzopardi, 2010; Jacobs et al., 2013; AlonsoAlconada et al., 2015). In addition, there are data indicating that hypothermia in low-income countries does not reduce mortality but rather it may aggravate prognosis in the presence of sepsis (Pauliah et al., 2013). Therefore, there is an urgent need to identify therapeutic agents effective to treat HIE.

Recent research focuses in the development of therapies that can be used in combination with hypothermia thus fostering synergy between therapeutic strategies (Hassell et al., 2015). They include erythropoietin (EPO), allopurinol, stem cells, noble gases, and melatonin. 


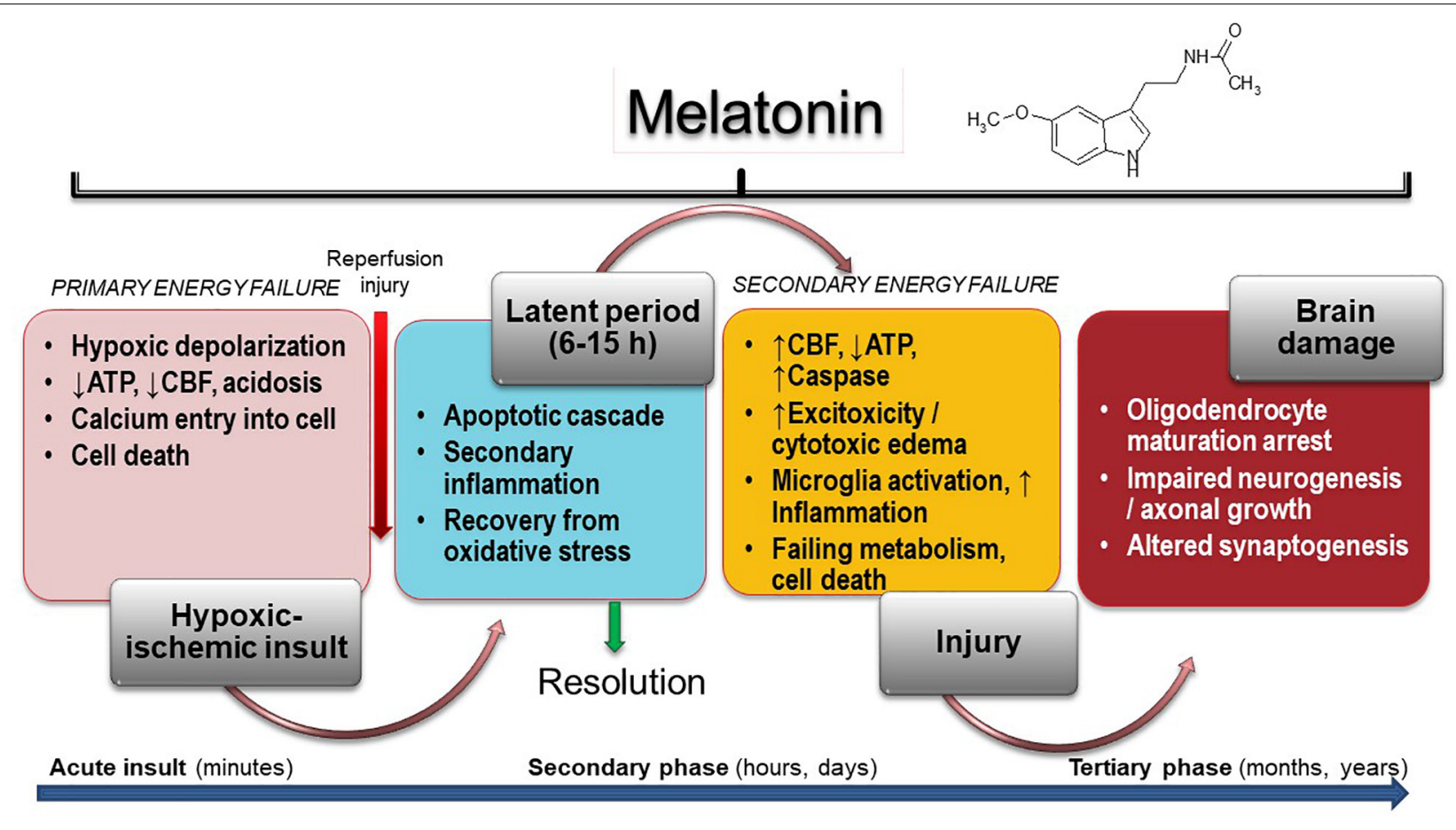

FIGURE 1 | Melatonin activity in HIE. Insult results in primary (acute phase) and secondary energy failure (secondary phase) in the brain while brain damage (tertiary phase) continues to occur months to years after the injury with decreased plasticity and reduced number of neurons. Melatonin has the unique property to cover all phases including attenuation of tertiary brain damage, hence expanding the therapeutic window to long-term outcome. CFB, cerebral blood flow.

Erythropoietin is a cytokine that is synthesized during the fetal period by the liver and postnatally by the kidney and the brain, and that acts as a growth factor and neuroprotective agent (Juul and Pet, 2015). The beneficial effect of EPO in HIE is based on its action on specific receptors present in neurons and glia, capable of developing a powerful antiapoptotic activity (favoring gene transcription of antiapoptotic, anti-inflammatory and antioxidant components) (Juul and Pet, 2015). Moreover, EPO promotes long term reparative phenomena like neurogenesis, oligodendrogenesis and angiogenesis (Jantzie et al., 2015). Up today, three phase III clinical trials are in progress on a total of 840 infants to assess the safety and efficacy of high doses of EPO $(1,000 \mathrm{U} / \mathrm{kg}$ ) in combination with hypothermia (Erythropoietin in Management of Neonatal Hypoxic Ischemic Encephalopathy, NCT03163589; High-dose Erythropoietin for Asphyxia and Encephalopathy, NCT02811263; Erythropoietin for Hypoxic Ischaemic Encephalopathy in Newborns, NCT03079167).

The inhibitory effect on xanthine oxidase, an enzyme involved in oxidative damage, is the base for the use of allopurinol as a therapy against HIE. In addition, allopurinol has the capacity to chelate free iron and acts as a scavenger of hydroxyl radicals (Ko and Godin, 1990). In a group of infants with severe HIE, the i.v. administration of $40 \mathrm{mg} / \mathrm{kg}$ of allopurinol decreased the formation of free radicals (Van et al., 1998). In line with these results, administration of allopurinol i.v. to the mother during the birth of fetuses with hypoxia or incipient hypoxia has been shown to reduce the blood levels of S-100 protein in the umbilical artery (a biomarker of cerebral damage) (Torrance et al., 2009).
A clinical trial is currently underway (Effect of Allopurinol for Hypoxic-ischemic Brain Injury on Neurocognitive Outcome, NCT03162653), to assess the therapeutic potential of allopurinol administered in the first minutes of life.

Interest in the use of stem cells to treat all kinds of diseases, among them HIE, is increasing (Nitkin et al., 2019). This therapy could facilitate repair and regeneration of damaged brain tissue after HI aggression via its interaction with immune system cells located in distant organs of the brain (e.g., spleen), thereby altering the immune/inflammatory response, as well as by interaction between the transplanted cells and the brain tissue to increase cell proliferation and neurogenesis (Bennet et al., 2012). Stem cell therapy of HIE, exclusive or associated with hypothermia, is still requires clinical trials to determine, among others, the most effective type of cells, the optimal dose and the most appropriate administration period for obtaining the best therapeutic results. One of these works in progress in the recruitment phase (Study of hCT-MSC in Newborn Infants With Moderate or Severe HIE, NCT03635450) will include a sample of 6 infants of 36 or more weeks of gestation with moderatesevere HIE, treated with hypothermia and infusion of two doses of stromal mesenchymal cells derived from umbilical cord.

Noble gases such as xenon and argon displayed neuroprotective activity in experimental models of HIE (Lobo et al., 2013). Their effect is mediated via their ability to decrease excitotoxicity by modulating glutamatergic NMDA receptors (Ma et al., 2007). The Total Body multicenter clinical trial hypothermia plus Xenon (TOBY-Xe) employed this gas plus 
hypothermia in 92 infants from 36 and 43 weeks (Azzopardi et al., 2016). To further examine some of the variables that may have influenced the treatment with this gas (i.e., dose or duration of treatment), a phase II clinical trial called CoolXenon3 Study (NCT02071394) is presently undergone.

Melatonin has been proposed as a promising strategy for HIE (Paprocka et al., 2019). A key point for melatonin efficacy to be used as therapy in HIE lies in its remarkable antioxidant and anti-inflammatory effects and in its capacity to cross readily the blood brain barrier (Hardeland et al., 2015; Reiter et al., 2017). Melatonin increased the level of protection developed by hypothermia by improving brain energy metabolism in a study employing piglets (Robertson et al., 2013). Clinically, treatment of asphyctic newborns with hypothermia and melatonin orally, reduces serum levels of oxidants more efficiently than hypothermia alone (Aly et al., 2015) and improved survival (Ahmad et al., 2018).

\section{BASIC BIOLOGY OF MELATONIN RELEVANT TO HIE}

Circulating melatonin is produced primarily by the pineal gland at night (Claustrat and Leston, 2015). It provides circadian and seasonal timing cues of the length of the night by acting as a chronobiotic (Pandi-Perumal et al., 2008). In addition, almost every cell in the body having mitochondria produces melatonin and the intracellular concentrations of melatonin are much higher than those circulating in blood (Venegas et al., 2012; Reiter et al., 2017; Suofu et al., 2017). Intracellular melatonin does not get the extracellular space and doses of melatonin much higher than those employed as a chronobiotic are needed to modify its intracellular levels (Cardinali, 2019a).

$\mathrm{MT}_{1}$ and $\mathrm{MT}_{2}$ melatonin receptors belong to the superfamily of membrane receptors associated with $\mathrm{G}$ proteins (G-protein coupled receptors, GPCR) (Dubocovich et al., 2010). Another GPCR member, GPR50, was recently added to the melatonin receptor subfamily displaying high sequence homology with $\mathrm{MT}_{1}$ and $\mathrm{MT}_{2}$ but showing null binding capacity to melatonin. Homoand heteromers among each other and also with other GPCRs are formed (Cecon et al., 2017).

Neuroprotection by melatonin is mediated via receptor and non-receptor mechanisms like antioxidant defense, improvement of energy metabolism and immune function, as well as anti-inflammatory, antiapoptotic and antiexcitotoxic effects (for ref. see Cardinali, 2019b).

Melatonin scavenges directly ROS (Hardeland et al., 1993; Reiter et al., 2000) and is further metabolized into strong antioxidant molecules (Galano et al., 2013; Tan et al., 2015). It also induces the upregulation of antioxidant enzymes like glutathione peroxidase, glutathione reductase, and superoxide dismutase (Fischer et al., 2013; Reiter et al., 2017). Melatonin decreases the release of pro-apoptotic proteins in response to injury and prevents apoptosis via stabilization of mitochondrial function (Tan and Reiter, 2019).

In rodent immature brain HI drives cell death via apoptosis through Bcl-2 family members (Morciano et al., 2016). As a consequence, mitochondria permeabilize, and proapoptotic factors, such as cytochrome $\mathrm{C}$ and the apoptosis-inducing factor are released into the cytoplasm. By increasing Bcl-2 protein expression and blocking Bax proapoptotic activity via the sirtuin (SIRT)-1/nuclear factor $\kappa \mathrm{B}(\mathrm{NF}-\kappa \mathrm{B})$ axis, melatonin inhibits significantly cytochrome $\mathrm{C}$ release and caspase 3 activation (Sun et al., 2002; Tan and Reiter, 2019).

Mitochondria permeabilize due to the opening of mitochondrial permeability transition pore (mPTP). This is a pathophysiological event that leads to mitochondrial depolarization, swelling, and the activation of the apoptotic and necrotic pathways (Morciano et al., 2017). Melatonin protects from mitochondrial swelling and membrane depolarization (Waseem et al., 2016) and prevents cytochrome $\mathrm{C}$ release and cardiolipin peroxidation (Petrosillo et al., 2009) in isolated rodent brain mitochondria subjected to $\mathrm{Ca}^{2+}$-induced mPTP.

Melatonin is also an immunological modulator that shows remarkable anti-inflammatory properties (Carrillo-Vico et al., 2013; Hardeland, 2018). Because these properties are observed in high-grade inflammation such as sepsis, ischemia/reperfusion and brain injury, and in the low-grade inflammation seen in neurodegenerative disorders and aging, the anti-inflammatory actions are of great medical interest. Melatonin inhibits the binding of NF- $\mathrm{BB}$ to DNA, thus decreasing the synthesis of proinflammatory signals (Carrillo-Vico et al., 2013). It also inhibits cyclooxygenase (Cox) (Cardinali et al., 1980), particularly Cox2 (Deng et al., 2006), and decreases mRNA of inducible nitric oxide synthase (Costantino et al., 1998). Among the several signaling pathways involved in the anti-inflammatory action of melatonin (Hardeland, 2018), the upregulation of SIRT-1, which shares various effects known from melatonin and further interferes with the proinflammatory signaling, is considered of major importance (Tan and Reiter, 2019). Ultimately, these effects of melatonin lead to down-regulation of proinflammatory and up-regulation of anti-inflammatory cytokines (Hardeland, 2018).

Anti-excitotoxic actions also arise after melatonin administration. Relevant to this, melatonin curtails neuronal death induced by the ionotropic glutamate receptor agonist kainate (Giusti et al., 1996). In addition, melatonin administration reduces the injury of hippocampal CA1 neurons brought about by ischemia (Cho et al., 1997) or by high doses of glucocorticoids (Furio et al., 2008). Melatonin antiexcitotoxic activity does not involve melatonin receptors (Escames et al., 2004).

Another neuroprotective mode of action involves the $\gamma$-aminobutyric acid (GABA)-ergic system. Melatonin has antiexcitatory, and at enough dosage, sedating effects via GABAergic mechanisms (Golombek et al., 1996; Caumo et al., 2009) exerted via allosteric modulation of melatonin of $\mathrm{GABA}_{\mathrm{A}}$ receptors (Cheng et al., 2012).

As far as a potential therapy for HIE in newborns, melatonin has many advantages. It crosses readily the blood-brain barrier, its antioxidant and anti-inflammatory effects are readily exerted and it has an excellent safety profile (Gitto et al., 2001, 2009; Welin et al., 2007; Foley and Steel, 2019). 
TABLE 1 | Melatonin activity in animal models of HIE.

\section{Findings \\ Melatonin provides neuroprotection in the late-gestation fetal sheep brain in response to umbilical cord occlusion \\ Melatonin protects from the long-term consequences of a neonatal hypoxic-ischemic brain injury in rats (behavioral asymmetry, learning deficits) \\ In 1-day-old Wistar rats subjected to hypoxia melatonin treatment reduced VEGF and NO levels as well as leakage of horseradish peroxidase in choroid plexus \\ Melatonin normalizes free iron, total isoprostanes, and total neuroprostanes in a rat model of neonatal $\mathrm{HI}$ encephalopathy \\ Melatonin was not able to reduce cortical infarct volume in a rat neonatal stroke model but strongly reduces inflammation and promotes subsequent myelination in the white matter \\ In neonatal rats subjected to $\mathrm{HI}$ melatonin reduced the percent infarcted brain volume and TUNEL positivity \\ Treatment with melatonin after neonatal $\mathrm{HI}$ in rats led to a neuroprotective effect reducing cell death, white matter demyelination and reactive astrogliosis}

Melatonin reduces oxidative stress and inflammatory cells recruitment and glial cells activation in cerebral cortex after neonatal $\mathrm{HI}$ damage of rats

In a neonatal rat model of $\mathrm{H}$ brain injury, melatonin, and topiramate, administered either alone or in combination significantly reduced the percent infarcted brain volume and number of TUNEL positive cells

In a piglet model of perinatal asphyxia, melatonin-augmented hypothermia significantly reduced the hypoxic-ischemic-induced increase of lactate/ $\mathrm{N}$-acetyl aspartate and lactate/total creatine ratios in the deep gray matter. Melatonin-augmented hypothermia increased levels of brain nucleotide triphosphate/exchangeable phosphate pool. Correlating with improved cerebral energy metabolism, TUNEL-positive nuclei were reduced in the hypothermia plus melatonin group compared with hypothermia alone in the thalamus, internal capsule, putamen and caudate, and there was reduced cleaved caspase 3 in the thalamus

In neonatal rats subjected to $\mathrm{HI}$, melatonin administration reduced the neuron splicing of XBP-1 mRNA, the increased phosphorylation of elF2 $\alpha$, and elevated expression of chaperone proteins GRP78 and Hsp70. Melatonin also prevented the depletion of SIRT-1 induced by $\mathrm{HI}$

Melatonin prevents cell death and mitochondrial dysfunction via a SIRT1-dependent mechanism during ischemic-stroke in mice

No improvement of neuronal metabolism in the reperfusion phase with melatonin treatment after $\mathrm{HI}$ brain injury in the neonatal rat was seen

In a neonatal rat model of $\mathrm{H}$ brain injury, the integrity of the auditory pathway in the brainstem was preserved by melatonin treatment

In a rat neonatal model of HIE, melatonin reduced necrotic cell death and decreased activation of the early phases of intrinsic apoptosis, with a concomitant increased expression and activity of SIRT1, reduced expression and acetylation of p53, and increased autophagy activation

Melatonin alleviates brain and peripheral tissue edema in a neonatal rat model of HIE, as assessed by expression of the edema related proteins AQP-4, ZO-1, and occludin

In postnatal day 7 rat pups subjected to unilateral $\mathrm{HI}$, pre-treatment with melatonin significantly reduced brain damage with $30 \%$ recovery in tissue loss compared to vehicle-treated animals. Autophagy and apoptotic cell death were significantly inhibited after melatonin treatment

Characterization of gene expression in the rat brainstem after neonatal $\mathrm{HI}$ injury melatonin has retarded effects on gene activation

After acute $\mathrm{HI}$ insult in preterm fetal sheep, melatonin administration decreased apoptosis, inflammation and oxidative stress within the white matter. It also increased oligodendrocyte cell number within the periventricular white matter only and improved myelin density within the subcortical but not the striatal white matter

Melatonin acts in synergy with hypothermia to reduce oxygen-glucose deprivation-induced cell death in rat hippocampal slices

Melatonin protects from newborn hypoxic-ischemic brain injury melatonin in murine experimental models through $\mathrm{MT}_{1}$ receptor

Repetitive neonatal melatonin treatment prevents from functional deficits in a rat model of cerebral palsy In a lamb model of perinatal asphyxia melatonin (i.v. or as a transdermal patch) alleviated acidosis and altered determinants of encephalopathy. Asphyxia significantly increased brain white and gray matter apoptotic cell death, lipid peroxidation and neuroinflammation, all effects mitigated by melatonin

Melatonin was administered at $2 \mathrm{~h}$ and $6 \mathrm{~h}$ after hypoxia-ischemia with cooling in a piglet model.

Neuroprotection was dose dependent; $15 \mathrm{mg} / \mathrm{kg}$ melatonin started $2 \mathrm{~h}$ after HI, given over $6 \mathrm{~h}$, was well tolerated and augmented hypothermic protection in sensorimotor cortex

\begin{tabular}{ll} 
Melatonin dose & References \\
\hline $\begin{array}{l}1 \mathrm{mg} \text { bolus i.v., then } \\
1 \mathrm{mg} / \mathrm{h} \text { for } 2 \mathrm{~h}\end{array}$ & Miller et al. (2005) \\
$15 \mathrm{mg} / \mathrm{kg}$ i.p. & Carloni et al. (2008) \\
$10 \mathrm{mg} / \mathrm{kg}$ i.p. & Sivakumar et al. (2008) \\
$15 \mathrm{mg} / \mathrm{kg}$ i.p. & Signorini et al. (2009) \\
$20 \mathrm{mg} / \mathrm{kg}$ i.p. (two & Villapol et al. (2011) \\
doses) & \\
$20 \mathrm{mg} / \mathrm{kg}$ i.p. & Cetinkaya et al. (2011) \\
$15 \mathrm{mg} / \mathrm{kg}$ i.p. & $\begin{array}{l}\text { Alonso-Alconada et al. } \\
\text { (2012) }\end{array}$ \\
$15 \mathrm{mg} / \mathrm{kg}$ i.p. & Balduini et al. (2012)
\end{tabular}

20 mg/kg i.p.

Ozyener et al. (2012)

$5 \mathrm{mg} / \mathrm{kg} / \mathrm{h}$ over $6 \mathrm{~h}$ started at $10 \mathrm{~min}$

after resuscitation

and repeated at $24 \mathrm{~h}$

$15 \mathrm{mg} / \mathrm{kg}$ i.p.

Carloni et al. (2014)

$10 \mathrm{mg} / \mathrm{kg}$ twice

Yang et al. (2015)

10 mg/kg i.p.

Berger et al. (2016)

15 mg/kg i.p.

Revuelta et al. (2016)

15 mg/kg i.p.

Carloni et al. (2017b)

10 mg/kg i.p.

Xu et al. (2017)

15 mg/kg i.p.

Hu et al. (2017)

15 mg/kg i.p.

Revuelta et al. (2017)

$0.2 \mathrm{mg}$ bolus i.v. to the fetus at $2 \mathrm{~h}$ after $\mathrm{HI}$ followed by an infusion of $0.1 \mathrm{mg} / \mathrm{h}$ for $24 \mathrm{~h}$

$25 \mu \mathrm{M}$

Carloni et al. (2018)

5-10 mg/kg i.p.

Sinha et al. (2018)

20 mg/kg i.p.

Jantzie et al. (2018)

$60 \mathrm{mg}$ in 24 h; i.v. or

Aridas et al. (2018)

transdermal patch

5 or $15 \mathrm{mg} / \mathrm{kg}$ i.v.

Robertson et al. (2019)

VEGF, vascular endothelial growth factor; NO, nitric oxide; AQP-4, aquaporin 4. 
TABLE 2 | Studies including treatment of HIE patients with melatonin.

\begin{tabular}{llll} 
Subjects & Design & Melatonin dose & Measured \\
\hline 20 asphyxiated newborns & Open-label study & $\begin{array}{l}10 \text { HIE newborns were treated } \\
\text { with a total of } 80 \mathrm{mg} \text { as eight oral }\end{array}$ & $\begin{array}{l}\text { Serum malondi-aldehyde and } \\
\text { nitrite/nitrate concentration }\end{array}$
\end{tabular}
with a total of $80 \mathrm{mg}$ as eight oral nitrite/nitrate concentration doses

74 preterm infants with respiratory distress syndrome

Open-label study

120 preterm infants with respiratory distress

syndrome

110 preterm infants with respiratory distress

syndrome

18 preterm infants

30 HIE newborns, 15

healthy newborns

15 preterm infants; 5 preterm infants with low dose, 5 preterm infants

with medium dose, 5

preterm infants with high

dose

\begin{abstract}
80 HIE newborns
\end{abstract}
Randomized

prospective trial

5 neonates with HIE

Open-label study
40 preterm infants were treated with a total of $100 \mathrm{mg} / \mathrm{kg}$ as 10 infusions

40 HIE newborns received

melatonin $10 \mathrm{mg}$ orally via

nasogastric tube at admission

IL-6, IL-8, TNF $\alpha$ in

tracheobronchial aspirate and

serum nitrite/nitrate concentratio

60 preterm infants were treated with a total of $100 \mathrm{mg} / \mathrm{kg}$ as 10

infusions

55 HIE newborns were treated with a total of $100 \mathrm{mg} / \mathrm{kg}$ as 10 infusions

Total of 0.04-0.6 $\mu \mathrm{g} / \mathrm{kg}$ over $0.5-6 \mathrm{~h}$ as an infusion

15 HIE newborns were treated with a total of $50 \mathrm{mg} / \mathrm{kg}$ as five daily enteral doses

Total of $0.5 \mathrm{mg} / \mathrm{kg}$ or $3 \mathrm{mg} / \mathrm{kg}$ or $15 \mathrm{mg} / \mathrm{kg}$ as 1 or 3 intragastric boluses

Serum IL-6, IL-8, TNF $\alpha$ and nitrite/nitrate concentration

IL-6, IL-8, TNF $\alpha$ in serum nitrite/nitrate concentration

Pharmaco-kinetic profiles

Serum melatonin, plasma SOD, serum NO, EEG, MRI, neurologic evaluations

Pharmacokinetic profiles

infused at $0.5 \mathrm{mg} / \mathrm{kg}$

Newborns were followed for 28 days to see the effect of melatonin in terms of survival rate Pharmacokinetic profiles trachea-bronchial aspirate and

Results

References

In the asphyxiated newborns given melatonin, there were significant reductions in malondialdehyde and nitrite/nitrate levels at both 12 and $24 \mathrm{~h}$. Three of the 10 asphyxiated children not given melatonin died within $72 \mathrm{~h}$ after birth; none of the 10 asphyxiated newborns given melatonin died

Compared with the melatonin-treated respiratory distress syndrome newborns, in the untreated infants the

concentrations of IL-6, IL-8, and TNF $\alpha$ 7 days after onset of the study were higher. In addition, nitrite/nitrate levels at all time points were higher in the untreated respiratory distress syndrome newborns than in the melatonin-treated babies

Melatonin treatment reduced the proinflammatory cytokines and improved the clinical outcome

Melatonin treatment reduced the proinflammatory cytokines and improved the clinical outcome

The pharmacokinetic profile of melatonin in preterm infants differs from that of adults so dosage of melatonin for preterm infants cannot be extrapolated from adult studies

At day 5 , the melatonin/hypothermia group had greater increase in melatonin and decline in $\mathrm{NO}$ and less decline in SOD. The melatonin/hypothermia group had fewer seizures on follow-up EEG and less white matter abnormalities on MRI. At 6 months, the melatonin/hypothermia group had improved survival without neurological or developmental abnormalities

A different pharmacokinetic profile in premature newborns, compared to adults. The high peak plasma concentrations and the long half-life indicate that in the neonatal clinical setting, it is possible to obtain and maintain high serum concentrations using a single administration of melatonin repeated every $12 / 24 \mathrm{~h}$ management of newborns with HIE led to improved survival rate

Melatonin half-life and clearance were prolonged, and the distribution volume decreased compared to adults. Hypothermia did not affect melatonin pharmacokinetics

Robertson et al. (2019)

Fulia et al. (2001)

Gitto et al. (2004b)

Gitto et al. (2004a)

Gitto et al. (2005)

Aly et al. (2015)

Ahmad et al. (2018)

Carloni et al. (2017a)

IL, interleukin; TNF, tumor necrosis factor; SOD, superoxide dismutase; NO, nitric oxide. 


\section{MELATONIN IN EXPERIMENTAL MODELS OF HIE}

Table 1 summarizes information on melatonin activity in animal models of HIE. With a few exceptions (Berger et al., 2016), a compelling amount of evidence supports the efficacy of melatonin on long-term consequences of a neonatal HI brain injury in rats and mice (behavioral asymmetry, learning deficits, etc.) (Jantzie et al., 2018).

Treatment with melatonin after neonatal HI in rats led to a neuroprotective effect reducing cell death, white matter demyelination and reactive astrogliosis (Alonso-Alconada et al., 2012; Hu et al., 2017). Melatonin prevents cell death and mitochondrial dysfunction via a SIRT1-dependent mechanism during ischemic-stroke (Yang et al., 2015; Carloni et al., 2017b). Melatonin reduced necrotic cell death and decreased activation of the early phases of intrinsic apoptosis, with a concomitant increased expression and activity of SIRT1, reduced expression and acetylation of $\mathrm{p} 53$ and increased autophagy activation (Xu et al., 2017).

The effect of melatonin was also apparent in other models of HIE. In a piglet model of perinatal asphyxia, melatoninaugmented hypothermia reduced the HI-induced increase of lactate $/ N$-acetyl aspartate and lactate/total creatine ratios in the deep gray matter. Apoptosis was reduced in the hypothermia plus melatonin group in the thalamus, internal capsule, putamen and caudate, and there was reduced cleaved caspase 3 in the thalamus (Robertson et al., 2013). In the late-gestation fetal sheep brain in response to umbilical cord occlusion melatonin provided neuroprotection by decreasing lipid peroxidation (Miller et al., 2005). In another study with acute HI insult in preterm fetal sheep, melatonin administration decreased apoptosis, inflammation and oxidative stress within the white matter (Yawno et al., 2017).

\section{MELATONIN IN HIE: CLINICAL STUDIES}

Table 2 summarizes melatonin-related clinical observations in HIE.

An initial observation indicated that in asphyxiated newborns with HIE, oral administration of melatonin $(80 \mathrm{mg}$ in eight doses) reduced serum malondialdehyde and nitrite/nitrate concentrations and improved survival (Fulia et al., 2001). Subsequent reports from the same group of investigators indicated that in preterm infants with respiratory distress the treatment with $100 \mathrm{mg} / \mathrm{kg}$ in 10 infusions improved the clinical outcome and reduced IL-6, IL-8, and TNF $\alpha$ concentrations in tracheobronchial aspirate and serum nitrite/nitrate concentration (Fulia et al., 2001; Gitto et al., 2004a,b, 2005; Hu et al., 2017; Revuelta et al., 2017; Yawno et al., 2017; Aridas et al., 2018; Carloni et al., 2018; Sinha et al., 2018; Robertson et al., 2019).

In a randomized prospective trial including $30 \mathrm{HIE}$ newborns treatment with $50 \mathrm{mg} / \mathrm{kg}$ of melatonin as five daily enteral doses the melatonin/hypothermia group had greater increase in melatonin and decline in circulating oxidants, fewer seizures in
EEG and less white matter abnormalities in magnetic resonance imaging. At 6 months, the melatonin/hypothermia group had improved survival without neurological or developmental abnormalities (Aly et al., 2015). A similar improvement of survival was reported in another randomized prospective trial including $40 \mathrm{HIE}$ newborns receiving melatonin $10 \mathrm{mg}$ orally via nasogastric tube (Ahmad et al., 2018).

Concerning the melatonin doses employed, it must be noted that the pharmacokinetic profile of melatonin in preterm infants differs from that of adults, making it impossible to applied allometric calculations for establishment of the optimal doses derived from studies in adults (Merchant et al., 2013). The high peak plasma concentrations and the long half-life of melatonin in newborn indicate that in the neonatal clinical setting, it is possible to obtain and maintain high serum concentrations of melatonin using a single administration repeated every 12/24 h (Carloni et al., 2017a). Moreover, hypothermia does not affect melatonin pharmacokinetics (Balduini et al., 2019).

\section{CONCLUDING REMARKS}

A remarkable number of melatonin effects strongly suggest that it may have an important role therapeutic role in HIE. Melatonin has antiexcitotoxic, anti-apoptotic, anti-inflammatory and antioxidant effects in a number of animal models of HIE and modulates normal glial development (Table 1). Clinically, randomized controlled pilot trials evaluating melatonin as an adjuvant to hypothermia in HIE indicated that the melatonin/hypothermia group show a reduced number of seizures, less evidence of white matter injury and a lower rate of mortality without developmental or neurological abnormalities (Aly et al., 2015; Ahmad et al., 2018).

Melatonin is remarkably non-toxic, and its safety is very high. The lethal dose 50 for the i.p. injection of melatonin was determined for rats and mice (1168 and $1131 \mathrm{mg} / \mathrm{kg}$ ), but failed to be measured after the oral administration of up to $3200 \mathrm{mg} / \mathrm{kg}$ to rats or of the s.c. injection of up to $1600 \mathrm{mg} / \mathrm{kg}$ to rats and mice (Sugden, 1983).

Melatonin shows a high safety profile in humans (Cardinali, 2019b; Foley and Steel, 2019) and, in general, is very well tolerated. Therefore, melatonin holds a promise in management of infants with HIE (Hendaus et al., 2016). Currently, the MELPRO study (NCT03806816) is in the process of recruiting patients, with the aim to include 100 newborns. This and additional phase III clinical trials are essential for the subsequent application of melatonin in newborn with HIE. Unfortunately, the pharmaceutical industry is refractive to support studies on melatonin because of the lack of protective patents for a natural compound. Hence, only with the involvement of governmental and non-profit organizations such a goal can be achieved.

\section{AUTHOR CONTRIBUTIONS}

The author confirms being the sole contributor of this work and has approved it for publication. 


\section{REFERENCES}

Ahmad, Q. M., Chishti, A. L., and Waseem, N. (2018). Role of melatonin in management of hypoxic ischaemic encephalopathy in newborns: a randomized control trial. J. Pak. Med. Assoc. 68, 1233-1237.

Alonso-Alconada, D., Alvarez, A., Lacalle, J., and Hilario, E. (2012). Histological study of the protective effect of melatonin on neural cells after neonatal hypoxia-ischemia. Histol. Histopathol. 27, 771-783. doi: 10.14670/HH-27.771

Alonso-Alconada, D., Broad, K. D., Bainbridge, A., Chandrasekaran, M., Faulkner, S. D., Kerenyi, A., et al. (2015). Brain cell death is reduced with cooling by 3.5 degrees $C$ to 5 degrees $C$ but increased with cooling by 8.5 degrees $C$ in a piglet asphyxia model. Stroke 46, 275-278. doi: 10.1161/STROKEAHA.114.007330

Aly, H., Elmahdy, H., El-Dib, M., Rowisha, M., Awny, M., El-Gohary, T., et al. (2015). Melatonin use for neuroprotection in perinatal asphyxia: a randomized controlled pilot study. J. Perinatol. 35, 186-191. doi: 10.1038/jp.2014.186

Aridas, J. D., McDonald, C. A., Paton, M. C., Yawno, T., Sutherland, A. E., Nitsos, I., et al. (2016). Cord blood mononuclear cells prevent neuronal apoptosis in response to perinatal asphyxia in the newborn lamb. J. Physiol. 594, 1421-1435. doi: 10.1113/JP271104

Aridas, J. D. S., Yawno, T., Sutherland, A. E., Nitsos, I., Ditchfield, M., Wong, F. Y., et al. (2018). Systemic and transdermal melatonin administration prevents neuropathology in response to perinatal asphyxia in newborn lambs. J. Pineal Res. 64:e12479. doi: 10.1111/jpi.12479

Azzopardi, D., Robertson, N. J., Bainbridge, A., Cady, E., Charles-Edwards, G., Deierl, A., et al. (2016). Moderate hypothermia within $6 \mathrm{~h}$ of birth plus inhaled xenon versus moderate hypothermia alone after birth asphyxia (TOBY-Xe): a proof-of-concept, open-label, randomised controlled trial. Lancet Neurol. 15, 145-153. doi: 10.1016/S1474-4422(15)00347-6

Balduini, W., Carloni, S., Perrone, S., Bertrando, S., Tataranno, M. L., Negro, S., et al. (2012). The use of melatonin in hypoxic-ischemic brain damage: an experimental study. J. Matern. Fetal Neonatal Med. 25(Suppl. 1), 119-124. doi: $10.3109 / 14767058.2012 .663232$

Balduini, W., Weiss, M. D., Carloni, S., Rocchi, M., Sura, L., Rossignol, C., et al. (2019). Melatonin pharmacokinetics and dose extrapolation after enteral infusion in neonates subjected to hypothermia. J. Pineal Res. 66:e12565. doi: 10.1111/jpi.12565

Bennet, L., Tan, S., Van den Heuij, L., Derrick, M., Groenendaal, F., Van, B. F., et al. (2012). Cell therapy for neonatal hypoxia-ischemia and cerebral palsy. Ann. Neurol. 71, 589-600. doi: 10.1002/ana.22670

Berger, H. R., Morken, T. S., Vettukattil, R., Brubakk, A. M., Sonnewald, U., and Wideroe, M. (2016). No improvement of neuronal metabolism in the reperfusion phase with melatonin treatment after hypoxic-ischemic brain injury in the neonatal rat. J. Neurochem. 136, 339-350. doi: 10.1111/jnc.13420

Burnard, E. D., and Cross, K. W. (1958). Rectal temperature in the newborn after birth asphyxia. Br. Med. J. 2, 1197-1199. doi: 10.1136/bmj.2.5106.1197

Cardinali, D. P. (2019a). Are melatonin doses employed clinically adequate for melatonin-induced cytoprotection? Melatonin. Res. 2, 106-132. doi: 10.32794/ mr11250025

Cardinali, D. P. (2019b). Melatonin: clinical perspectives in neurodegeneration. Front. Endocrinol. 10:480. doi: 10.3389/fendo.2019.00480

Cardinali, D. P., Ritta, M. N., Fuentes, A. M., Gimeno, M. F., and Gimeno, A. L. (1980). Prostaglandin E release by rat medial basal hypothalamus in vitro. Inhibition by melatonin at submicromolar concentrations. Eur. J. Pharmacol. 67, 151-153. doi: 10.1016/0014-2999(80)90025-4

Carloni, S., Albertini, M. C., Galluzzi, L., Buonocore, G., Proietti, F., and Balduini, W. (2014). Melatonin reduces endoplasmic reticulum stress and preserves sirtuin 1 expression in neuronal cells of newborn rats after hypoxia-ischemia. J. Pineal Res. 57, 192-199. doi: 10.1111/jpi.12156

Carloni, S., Facchinetti, F., Pelizzi, N., Buonocore, G., and Balduini, W. (2018). Melatonin acts in synergy with hypothermia to reduce oxygen-glucose deprivation-induced cell death in rat hippocampus organotypic slice cultures. Neonatology 114, 364-371. doi: 10.1159/000491859

Carloni, S., Perrone, S., Buonocore, G., Longini, M., Proietti, F., and Balduini, W. (2008). Melatonin protects from the long-term consequences of a neonatal hypoxic-ischemic brain injury in rats. J. Pineal Res. 44, 157-164. doi: 10.1111/j. 1600-079X.2007.00503.x

Carloni, S., Proietti, F., Rocchi, M., Longini, M., Marseglia, L., D’Angelo, G., et al. (2017a). Melatonin pharmacokinetics following oral administration in preterm neonates. Molecules 22:E2115. doi: 10.3390/molecules22122115
Carloni, S., Riparini, G., Buonocore, G., and Balduini, W. (2017b). Rapid modulation of the silent information regulator 1 by melatonin after hypoxiaischemia in the neonatal rat brain. J. Pineal Res. 63:e12434. doi: 10.1111/jpi. 12434

Carrillo-Vico, A., Lardone, P. J., Alvarez-Sanchez, N., Rodriguez-Rodriguez, A., and Guerrero, J. M. (2013). Melatonin: buffering the immune system. Int. J. Mol. Sci. 14, 8638-8683. doi: 10.3390/ijms14048638

Castillo-Melendez, M., Baburamani, A. A., Cabalag, C., Yawno, T., Witjaksono, A., Miller, S. L., et al. (2013). Experimental modelling of the consequences of brief late gestation asphyxia on newborn lamb behaviour and brain structure. PLoS One 8:e77377. doi: 10.1371/journal.pone.0077377

Castillo-Melendez, M., Chow, J. A., and Walker, D. W. (2004). Lipid peroxidation, caspase-3 immunoreactivity, and pyknosis in late-gestation fetal sheep brain after umbilical cord occlusion. Pediatr. Res. 55, 864-871. doi: 10.1203/01.PDR. 0000115679.86566.C4

Caumo, W., Levandovski, R., and Hidalgo, M. P. (2009). Preoperative anxiolytic effect of melatonin and clonidine on postoperative pain and morphine consumption in patients undergoing abdominal hysterectomy: a double-blind, randomized, placebo-controlled study. J. Pain 10, 100-108. doi: 10.1016/j.jpain. 2008.08.007

Cecon, E., Oishi, A., and Jockers, R. (2017). Melatonin receptors: molecular pharmacology and signalling in the context of system bias. Br. J. Pharmacol. 175, 3263-3280. doi: 10.1111/bph.13950

Cetinkaya, M., Alkan, T., Ozyener, F., Kafa, I. M., Kurt, M. A., and Koksal, N. (2011). Possible neuroprotective effects of magnesium sulfate and melatonin as both pre- and post-treatment in a neonatal hypoxic-ischemic rat model. Neonatology 99, 302-310. doi: 10.1159/000320643

Cheng, X. P., Sun, H., Ye, Z. Y., and Zhou, J. N. (2012). Melatonin modulates the GABAergic response in cultured rat hippocampal neurons. J. Pharmacol. Sci. 119, 177-185. doi: 10.1254/jphs.11183fp

Cho, S., Joh, T. H., Baik, H. H., Dibinis, C., and Volpe, B. T. (1997). Melatonin administration protects CA1 hippocampal neurons after transient forebrain ischemia in rats. Brain Res. 755, 335-338. doi: 10.1016/s0006-8993(97)00188-1

Claustrat, B., and Leston, J. (2015). Melatonin: physiological effects in humans. Neurochirurgie 61, 77-84. doi: 10.1016/j.neuchi.2015.03.002

Costantino, G., Cuzzocrea, S., Mazzon, E., and Caputi, A. P. (1998). Protective effects of melatonin in zymosan-activated plasma-induced paw inflammation. Eur. J. Pharmacol. 363, 57-63. doi: 10.1016/s0014-2999(98)00673-6

Deng, W. G., Tang, S. T., Tseng, H. P., and Wu, K. K. (2006). Melatonin suppresses macrophage cyclooxygenase- 2 and inducible nitric oxide synthase expression by inhibiting p52 acetylation and binding. Blood 108, 518-524. doi: 10.1182/ blood-2005-09-3691

du Plessis, A. J., and Volpe, J. J. (2002). Perinatal brain injury in the preterm and term newborn. Curr. Opin. Neurol. 15, 151-157. doi: 10.1097/00019052200204000-00005

Dubocovich, M. L., Delagrange, P., Krause, D. N., Sugden, D., Cardinali, D. P., and Olcese, J. (2010). International Union Of Basic and clinical pharmacology. LXXV. nomenclature, classification, and pharmacology of G protein-coupled melatonin receptors. Pharmacol. Rev. 62, 343-380. doi: 10.1124/pr.110.002832

Escames, G., Leon, J., Lopez, L. C., and Acuña-Castroviejo, D. (2004). Mechanisms of N-methyl-D-aspartate receptor inhibition by melatonin in the rat striatum. J. Neuroendocrinol. 16, 929-935. doi: 10.1111/j.1365-2826.2004.01250.x

Fischer, T. W., Kleszczynski, K., Hardkop, L. H., Kruse, N., and Zillikens, D. (2013). Melatonin enhances antioxidative enzyme gene expression (CAT, GPx, SOD), prevents their UVR-induced depletion, and protects against the formation of DNA damage (8-hydroxy-2' -deoxyguanosine) in ex vivo human skin. J. Pineal Res. 54, 303-312. doi: 10.1111/jpi.12018

Fleiss, B., and Gressens, P. (2012). Tertiary mechanisms of brain damage: a new hope for treatment of cerebral palsy? Lancet Neurol. 11, 556-566. doi: 10.1016/ S1474-4422(12)70058-3

Foley, H. M., and Steel, A. E. (2019). Adverse events associated with oral administration of melatonin: a critical systematic review of clinical evidence. Complement. Ther. Med. 42, 65-81. doi: 10.1016/j.ctim.2018.11.003

Fulia, F., Gitto, E., Cuzzocrea, S., Reiter, R. J., Dugo, L., Gitto, P., et al. (2001). Increased levels of malondialdehyde and nitrite/nitrate in the blood of asphyxiated newborns: reduction by melatonin. J. Pineal Res. 31, 343-349. doi: 10.1034/j.1600-079x.2001.310409.x

Furio, A. M., Fontao, R., Falco, N., Ruiz, J. I., Caccuri, R. L., and Cardinali, D. P. (2008). Neuroprotective effect of melatonin on glucocorticoid toxicity in the 
rat hippocampus. Open Physiol. J. 1, 23-27. doi: 10.2174/187436090080101 0023

Galano, A., Tan, D. X., and Reiter, R. J. (2013). On the free radical scavenging activities of melatonin's metabolites. AFMK and AMK. J. Pineal Res. 54, 245257. doi: $10.1111 /$ jpi.12010

Gitto, E., Karbownik, M., Reiter, R. J., Tan, D. X., Cuzzocrea, S., Chiurazzi, P., et al. (2001). Effects of melatonin treatment in septic newborns. Pediatr. Res. 50, 756-760. doi: 10.1203/00006450-200112000-00021

Gitto, E., Pellegrino, S., Gitto, P., Barberi, I., and Reiter, R. J. (2009). Oxidative stress of the newborn in the pre- and postnatal period and the clinical utility of melatonin. J. Pineal Res. 46, 128-139. doi: 10.1111/j.1600-079X.2008. 00649.x

Gitto, E., Reiter, R. J., Amodio, A., Romeo, C., Cuzzocrea, E., Sabatino, G., et al. (2004a). Early indicators of chronic lung disease in preterm infants with respiratory distress syndrome and their inhibition by melatonin. J. Pineal Res. 36, 250-255. doi: 10.1111/j.1600-079X.2004.00124.x

Gitto, E., Reiter, R. J., Cordaro, S. P., La, R. M., Chiurazzi, P., Trimarchi, G., et al. (2004b). Oxidative and inflammatory parameters in respiratory distress syndrome of preterm newborns: beneficial effects of melatonin. Am. J. Perinatol. 21, 209-216. doi: 10.1055/s-2004-828610

Gitto, E., Reiter, R. J., Sabatino, G., Buonocore, G., Romeo, C., Gitto, P., et al. (2005). Correlation among cytokines, bronchopulmonary dysplasia and modality of ventilation in preterm newborns: improvement with melatonin treatment. J. Pineal Res. 39, 287-293. doi: 10.1111/j.1600-079X.2005.00251.x

Giusti, P., Lipartiti, M., Franceschini, D., Schiavo, N., Floreani, M., and Manev, H. (1996). Neuroprotection by melatonin from kainate-induced excitotoxicity in rats. FASEB J. 10, 891-896. doi: 10.1096/fasebj.10.8.8666166

Golombek, D. A., Pevet, P., and Cardinali, D. P. (1996). Melatonin effects on behavior: possible mediation by the central GABAergic system. Neurosci. Biobehav. Rev. 20, 403-412. doi: 10.1016/0149-7634(95)00052-6

Hardeland, R. (2018). Melatonin and inflammation-Story of a double-edged blade. J. Pineal Res. 65 :e12525. doi: 10.1111/jpi.12525

Hardeland, R., Cardinali, D. P., Brown, G. M., and Pandi-Perumal, S. R. (2015). Melatonin and brain inflammaging. Prog. Neurobiol. 12, 46-63. doi: 10.1016/j. pneurobio.2015.02.001

Hardeland, R., Reiter, R. J., Poeggeler, B., and Tan, D. X. (1993). The significance of the metabolism of the neurohormone melatonin: antioxidative protection and formation of bioactive substances. Neurosci. Biobehav. Rev. 17, 347-357. doi: 10.1016/s0149-7634(05)80016-8

Hassell, K. J., Ezzati, M., Alonso-Alconada, D., Hausenloy, D. J., and Robertson, N. J. (2015). New horizons for newborn brain protection: enhancing endogenous neuroprotection. Arch. Dis. Child. Fetal Neonatal Ed. 100, F541F552. doi: 10.1136/archdischild-2014-306284

Hendaus, M. A., Jomha, F. A., and Alhammadi, A. H. (2016). Melatonin in the management of perinatal hypoxic-ischemic encephalopathy: light at the end of the tunnel? Neuropsychiatr. Dis. Treat 12, 2473-2479. doi: 10.2147/NDT. S115533

Hu, Y., Wang, Z., Liu, Y., Pan, S., Zhang, H., Fang, M., et al. (2017). Melatonin reduces hypoxic-ischaemic (HI) induced autophagy and apoptosis: an in vivo and in vitro investigation in experimental models of neonatal $\mathrm{HI}$ brain injury. Neurosci. Lett. 653, 105-112. doi: 10.1016/j.neulet.2016.11.050

Jacobs, S. E., Berg, M., Hunt, R., Tarnow-Mordi, W. O., Inder, T. E., and Davis, P. G. (2013). Cooling for newborns with hypoxic ischaemic encephalopathy. Cochrane Database Syst. Rev. 31:CD003311. doi: 10.1002/14651858.CD003311. pub3

Jantzie, L. L., Corbett, C. J., Firl, D. J., and Robinson, S. (2015). Postnatal erythropoietin mitigates impaired cerebral cortical development following subplate loss from prenatal hypoxia-ischemia. Cereb. Cortex 25, 2683-2695. doi: 10.1093/cercor/bhu066

Jantzie, L. L., Oppong, A. Y., Conteh, F. S., Yellowhair, T. R., Kim, J., Fink, G., et al. (2018). repetitive neonatal erythropoietin and melatonin combinatorial treatment provides sustained repair of functional deficits in a rat model of cerebral palsy. Front. Neurol. 9:233. doi: 10.3389/fneur.2018.00233

Juul, S. E., and Pet, G. C. (2015). Erythropoietin and neonatal neuroprotection. Clin. Perinatol. 42, 469-481. doi: 10.1016/j.clp.2015.04.004

Ko, K. M., and Godin, D. V. (1990). Inhibition of transition metal ion-catalysed ascorbate oxidation and lipid peroxidation by allopurinol and oxypurinol. Biochem. Pharmacol. 40, 803-809. doi: 10.1016/0006-2952(90)90319-g
Laptook, A. R., Corbett, R. J., Sterett, R., Garcia, D., and Tollefsbol, G. (1995). Quantitative relationship between brain temperature and energy utilization rate measured in vivo using $31 \mathrm{P}$ and $1 \mathrm{H}$ magnetic resonance spectroscopy. Pediatr. Res. 38, 919-925. doi: 10.1203/00006450-199512000-00015

Lawn, J., Shibuya, K., and Stein, C. (2005). No cry at birth: global estimates of intrapartum stillbirths and intrapartum-related neonatal deaths. Bull. World Health Organ. 83, 409-417.

Lobo, N., Yang, B., Rizvi, M., and Ma, D. (2013). Hypothermia and xenon: novel noble guardians in hypoxic-ischemic encephalopathy? J. Neurosci. Res. 91, 473-478. doi: 10.1002/jnr.23178

Ma, D., Williamson, P., Januszewski, A., Nogaro, M. C., Hossain, M., Ong, L. P., et al. (2007). Xenon mitigates isoflurane-induced neuronal apoptosis in the developing rodent brain. Anesthesiology 106, 746-753. doi: 10.1097/01.anes. 0000264762.48920 .80

Martinez-Biarge, M., Ferriero, D. M., and Cowan, F. M. (2019). Perinatal arterial ischemic stroke. Handb. Clin. Neurol. 162, 239-266. doi: 10.1016/B978-0-44464029-1.00011-4

Merchant, N. M., Azzopardi, D. V., Hawwa, A. F., McElnay, J. C., Middleton, B., Arendt, J., et al. (2013). Pharmacokinetics of melatonin in preterm infants. $B r$. J. Clin. Pharmacol. 76, 725-733. doi: 10.1111/bcp.12092

Miller, S. L., Wallace, E. M., and Walker, D. W. (2012). Antioxidant therapies: a potential role in perinatal medicine. Neuroendocrinology 96, 13-23. doi: 10. $1159 / 000336378$

Miller, S. L., Yan, E. B., Castillo-Melendez, M., Jenkin, G., and Walker, D. W. (2005). Melatonin provides neuroprotection in the late-gestation fetal sheep brain in response to umbilical cord occlusion. Dev. Neurosci. 27, 200-210. doi: $10.1159 / 000085993$

Morciano, G., Bonora, M., Campo, G., Aquila, G., Rizzo, P., Giorgi, C., et al. (2017). Mechanistic role of mPTP in ischemia-reperfusion injury. Adv. Exp. Med. Biol. 982, 169-189. doi: 10.1007/978-3-319-55330-6-9

Morciano, G., Pedriali, G., Sbano, L., Iannitti, T., Giorgi, C., and Pinton, P. (2016). Intersection of mitochondrial fission and fusion machinery with apoptotic pathways: role of Mcl-1. Biol. Cell 108, 279-293. doi: 10.1111/boc.2016 00019

Nitkin, C. R., Rajasingh, J., Pisano, C., Besner, G. E., Thebaud, B., and Sampath, V. (2019). Stem cell therapy for preventing neonatal diseases in the 21st century: current understanding and challenges. Pediatr. Res. doi: 10.1038/s41390-0190425-5 [Epub ahead of print].

Ozyener, F., Cetinkaya, M., Alkan, T., Goren, B., Kafa, I. M., Kurt, M. A., et al. (2012). Neuroprotective effects of melatonin administered alone or in combination with topiramate in neonatal hypoxic-ischemic rat model. Restor. Neurol. Neurosci. 30, 435-444. doi: 10.3233/RNN-2012-120217

Pandi-Perumal, S. R., Trakht, I., Srinivasan, V., Spence, D. W., Maestroni, G. J. M., Zisapel, N., et al. (2008). Physiological effects of melatonin: role of melatonin receptors and signal transduction pathways. Progr. Neurobiol. 185, 335-353. doi: 10.1016/j.pneurobio.2008.04.001

Paprocka, J., Kijonka, M., Rzepka, B., and Sokol, M. (2019). Melatonin in hypoxic-ischemic brain injury in term and preterm babies. Int. J. Endocrinol. 2019:9626715. doi: 10.1155/2019/9626715

Pauliah, S. S., Shankaran, S., Wade, A., Cady, E. B., and Thayyil, S. (2013). Therapeutic hypothermia for neonatal encephalopathy in low- and middleincome countries: a systematic review and meta-analysis. PLoS One 8:e58834. doi: 10.1371/journal.pone.0058834

Petrosillo, G., Moro, N., Ruggiero, F. M., and Paradies, G. (2009). Melatonin inhibits cardiolipin peroxidation in mitochondria and prevents the mitochondrial permeability transition and cytochrome $\mathrm{c}$ release. Free Radic Biol. Med. 47, 969-974. doi: 10.1016/j.freeradbiomed.2009.06.032

Pregnolato, S., Chakkarapani, E., Isles, A. R., and Luyt, K. (2019). Glutamate transport and preterm brain injury. Front. Physiol. 10:417. doi: 10.3389/fphys. 2019.00417

Reiter, R. J., Rosales-Corral, S., Tan, D. X., Jou, M. J., Galano, A., and Xu, B. (2017). Melatonin as a mitochondria-targeted antioxidant: one of evolution's best ideas. Cell Mol. Life. Sci. 74, 3863-3881. doi: 10.1007/s00018-017-2609-7

Reiter, R. J., Tan, D. X., Osuna, C., and Gitto, E. (2000). Actions of melatonin in the reduction of oxidative stress. A review. J. Biomed. Sci. 7, 444-458. doi: $10.1007 / \mathrm{bf} 02253360$

Revuelta, M., Arteaga, O., Alvarez, A., Martinez-Ibarguen, A., and Hilario, E. (2017). characterization of gene expression in the rat brainstem after neonatal 
hypoxic-ischemic injury and antioxidant treatment. Mol. Neurobiol. 54, 11291143. doi: 10.1007/s12035-016-9724-6

Revuelta, M., Arteaga, O., Montalvo, H., Alvarez, A., Hilario, E., and MartinezIbarguen, A. (2016). Antioxidant treatments recover the alteration of auditoryevoked potentials and reduce morphological damage in the inferior colliculus after perinatal asphyxia in rat. Brain Pathol. 26, 186-198. doi: 10.1111/bpa. 12272

Robertson, N. J., Faulkner, S., Fleiss, B., Bainbridge, A., Andorka, C., Price, D., et al. (2013). Melatonin augments hypothermic neuroprotection in a perinatal asphyxia model. Brain 136, 90-105. doi: 10.1093/brain/aws285

Robertson, N. J., Martinello, K., Lingam, I., Avdic-Belltheus, A., Meehan, C., Alonso-Alconada, D., et al. (2019). Melatonin as an adjunct to therapeutic hypothermia in a piglet model of neonatal encephalopathy: a translational study. Neurobiol. Dis. 121, 240-251. doi: 10.1016/j.nbd.2018.10.004

Roka, A., and Azzopardi, D. (2010). Therapeutic hypothermia for neonatal hypoxic ischaemic encephalopathy. Early. Hum. Dev. 86, 361-367. doi: 10.1016/j. earlhumdev.2010.05.013

Schreglmann, M., Ground, A., Vollmer, B., and Johnson, M. J. (2019). Systematic review: long-term cognitive and behavioural outcomes of neonatal hypoxicischaemic encephalopathy in children without cerebral palsy. Acta Paediatr. doi: 10.1111/apa.14821 [Epub ahead of print].

Signorini, C., Ciccoli, L., Leoncini, S., Carloni, S., Perrone, S., Comporti, M., et al. (2009). Free iron, total F-isoprostanes and total F-neuroprostanes in a model of neonatal hypoxic-ischemic encephalopathy: neuroprotective effect of melatonin. J. Pineal Res. 46, 148-154. doi: 10.1111/j.1600-079X.2008.00639.x

Sinha, B., Wu, Q., Li, W., Tu, Y., Sirianni, A. C., Chen, Y., et al. (2018). Protection of melatonin in experimental models of newborn hypoxic-ischemic brain injury through MT1 receptor. J. Pineal Res. 64:e12443. doi: 10.1111/jpi.12443

Sivakumar, V., Lu, J., Ling, E. A., and Kaur, C. (2008). Vascular endothelial growth factor and nitric oxide production in response to hypoxia in the choroid plexus in neonatal brain. Brain Pathol. 18, 71-85. doi: 10.1111/j.17503639.2007.00104.x

Sugden, D. (1983). Psychopharmacological effects of melatonin in mouse and rat. J. Pharmacol. Exp. Ther. 227, 587-591.

Sun, F. Y., Lin, X., Mao, L. Z., Ge, W. H., Zhang, L. M., Huang, Y. L., et al. (2002). Neuroprotection by melatonin against ischemic neuronal injury associated with modulation of DNA damage and repair in the rat following a transient cerebral ischemia. J. Pineal Res. 33, 48-56. doi: 10.1034/j.1600-079x.2002.01891.x

Suofu, Y., Li, W., Jean-Alphonse, F. G., Jia, J., Khattar, N. K., Li, J., et al. (2017). Dual role of mitochondria in producing melatonin and driving GPCR signaling to block cytochrome c release. Proc. Natl. Acad. Sci. U.S.A. 114, E7997-E8006. doi: 10.1073/pnas.1705768114

Tan, D. X., Manchester, L. C., Esteban-Zubero, E., Zhou, Z., and Reiter, R. J. (2015). Melatonin as a potent and inducible endogenous antioxidant: synthesis and metabolism. Molecules 20, 18886-18906. doi: 10.3390/molecules201018886

Tan, D. X., and Reiter, R. J. (2019). Mitochondria: the birth place, the battle ground and the site of melatonin metabolism. Melatonin Res. 2, 44-66. doi: 10.32794/ mr11250011

Torrance, H. L., Benders, M. J., Derks, J. B., Rademaker, C. M., Bos, A. F., Van Den Berg, P., et al. (2009). Maternal allopurinol during fetal hypoxia lowers cord blood levels of the brain injury marker S-100B. Pediatrics 124, 350-357. doi: $10.1542 /$ peds.2008-2228

Torres-Cuevas, I., Corral-Debrinski, M., and Gressens, P. (2019). Brain oxidative damage in murine models of neonatal hypoxia/ischemia and reoxygenation. Free Radic Biol. Med. 142, 3-15. doi: 10.1016/j.freeradbiomed.2019.06.011
Van, B. F., Shadid, M., Moison, R. M., Dorrepaal, C. A., Fontijn, J., Monteiro, L., et al. (1998). Effect of allopurinol on postasphyxial free radical formation, cerebral hemodynamics, and electrical brain activity. Pediatrics 101, 185-193. doi: $10.1542 /$ peds.101.2.185

Venegas, C., Garcia, J. A., Escames, G., Ortiz, F., Lopez, A., Doerrier, C., et al. (2012). Extrapineal melatonin: analysis of its subcellular distribution and daily fluctuations. J. Pineal Res. 52, 217-227. doi: 10.1111/j.1600-079X.2011. 00931.x

Villapol, S., Fau, S., Renolleau, S., Biran, V., Charriaut-Marlangue, C., and Baud, O. (2011). Melatonin promotes myelination by decreasing white matter inflammation after neonatal stroke. Pediatr. Res. 69, 51-55. doi: 10.1203/PDR. 0b013e3181fcb40b

Waseem, M., Tabassum, H., and Parvez, S. (2016). Melatonin modulates permeability transition pore and 5-hydroxydecanoate induced KATP channel inhibition in isolated brain mitochondria. Mitochondrion 31, 1-8. doi: 10.1016/ j.mito.2016.08.005

Welin, A. K., Svedin, P., Lapatto, R., Sultan, B., Hagberg, H., Gressens, P., et al. (2007). Melatonin reduces inflammation and cell death in white matter in the mid-gestation fetal sheep following umbilical cord occlusion. Pediatr. Res. 61, 153-158. doi: 10.1203/01.pdr.0000252546.204 $51.1 \mathrm{a}$

World Health Organization [WHO], (2015). Health in 2015: From MDGs, Millennium Development Goals to SDGs, Sustainable Development Goals. Geneva: World Health Organization [WHO].

Xu, L. X., Lv, Y., Li, Y. H., Ding, X., Wang, Y., Han, X., et al. (2017). Melatonin alleviates brain and peripheral tissue edema in a neonatal rat model of hypoxicischemic brain damage: the involvement of edema related proteins. BMC Pediatr. 17:90. doi: 10.1186/s12887-017-0824-x

Yan, E. B., Unthank, J. K., Castillo-Melendez, M., Miller, S. L., Langford, S. J., and Walker, D. W. (2005). Novel method for in vivo hydroxyl radical measurement by microdialysis in fetal sheep brain in utero. J. Appl. Physiol. 98, 2304-2310. doi: 10.1152/japplphysiol.00617.2004

Yang, Y., Jiang, S., Dong, Y., Fan, C., Zhao, L., Yang, X., et al. (2015). Melatonin prevents cell death and mitochondrial dysfunction via a SIRT1-dependent mechanism during ischemic-stroke in mice. J. Pineal Res. 58, 61-70. doi: 10. 1111/jpi.12193

Yawno, T., Mahen, M., Li, J., Fahey, M. C., Jenkin, G., and Miller, S. L. (2017). The beneficial effects of melatonin administration following hypoxia-ischemia in preterm fetal sheep. Front. Cell Neurosci. 11:296. doi: 10.3389/fncel.2017. 00296

Yildiz, E. P., Ekici, B., and Tatli, B. (2017). Neonatal hypoxic ischemic encephalopathy: an update on disease pathogenesis and treatment. Expert. Rev. Neurother. 17, 449-459. doi: 10.1080/14737175.2017.125 9567

Conflict of Interest: The author declares that the research was conducted in the absence of any commercial or financial relationships that could be construed as a potential conflict of interest.

Copyright (C) 2019 Cardinali. This is an open-access article distributed under the terms of the Creative Commons Attribution License (CC BY). The use, distribution or reproduction in other forums is permitted, provided the original author(s) and the copyright owner(s) are credited and that the original publication in this journal is cited, in accordance with accepted academic practice. No use, distribution or reproduction is permitted which does not comply with these terms. 